
work is properly cited

\title{
PRONIOSOMES: A KEY TO IMPROVED DRUG DELIVERY
}

\author{
*Rekha Kumari ${ }^{1}$, Kuldeep Varma ${ }^{1}$, Aatish Verma ${ }^{2}$, Girish Kumar Yadav ${ }^{3}$, Sheo Datta Maurya ${ }^{1}$ \\ ${ }^{1}$ Department of Pharmacy, IEC Group of Institutions, Greater Noida, INDIA - 201308 \\ ${ }^{2}$ QC Chemist, Ind Swift Lab. Ltd., Derabassi, Mohali, Punjab \\ ${ }^{3}$ Sr. Executive QA, Acme Formulation, Nalagarh, Solan, Himachal Pradesh
}

\begin{abstract}
:
In the recent years nanotechnology has brought revolutionary changes in the field of life sciences which includes novel drug delivery systems, diagnostics, nutraceuticals and biomedicals for implants and prosthesis. Sustained and Controlled release drug products are often formulated to permit the establishment and maintenance of drug concentration at site of action for longer interval of time such as liposomes, niosomes, ethosomes, transferosomes, etc. 'Proniosomal technique' is the one among them. Proniosomes are dry products derived from niosomes. They are water soluble carrier particles that are coated with surfactant and can be hydrated to form niosomal dispersion immediately before use on brief agitation in hot aqueous media. They are being used in order to minimize the problems associated with niosome's physical stability such as aggregation, fusion, leaking and to provide additional convenience in transportation, distribution, storage and dosing etc. In all comparisons, proniosomes are more promising than conventional niosomes.
\end{abstract}

Keywords: Proniosomes, Niosomes, Liposomes, Stability, Drug release

\section{INTRODUCTION:}

Considerable hard work has been done on the development of new drug delivery system named Controlled Drug Delivery System. It has prolonged action formulations giving continuous release of their active ingredients at a predetermined rate and predetermined time. The vital objective for the development of controlled release dosage forms is to prolong the duration of action, increase safety margin of high potency drugs due to better control of plasma levels, reduce fluctuations in plasma concentration, reduce serious side effects and to provide assurance for higher patient compliance ${ }^{1}$.

Approaches are being adopted to achieve these goals by paying considerable attention either towards controlling the distribution of drug by incorporating it in a carrier system, or altering the structure of the drug at the molecular level, or controlling the input of the drug into the bioenvironment to ensure an appropriate profile of distribution.

In past few decades vesicles have become the vehicles of choice in drug delivery. Lipid vesicles are found to be of value in immunology, membrane biology, diagonistic techniques, and most recently, genetic engineering. Vesicles can play a major role in modeling biological membranes and in the transport and targeting of active agents. Encapsulation of drug in vesicular structures can be predicted to prolong the existence of drug in systematic circulation and perhaps, reduce the toxicity if selective uptake can be achieved. The phagocytic uptake of systemic delivery of the drug loaded vesicular delivery system provides efficient methods for delivery of drug directly to the site of infection, leading to the reduction of drug toxicity with no adverse effects. Vesicular drug delivery reduces the cost of therapy by improving bioavailability of medication, especially in case of poorly soluble drugs. They can incorporate both hydrophilic and lipophilic drugs. These systems delay drug elimination of rapidly metabolisable drugs, functions as sustained release systems and solve the problems of drug's insolubility, instability and rapid degradation. Consequently a number of vesicular delivery systems such as liposomes, transferosomes, pharmacosomes, neosomes or preniosomes, emulsomes etc, have been developed.

Many synthetic amphiphiles form vesicles, but as most are ionic and relatively toxic, they are generally unsuitable for use as drug carrier vesicles. Formation by some members of dialkyl poly-oxyethylene ether nonionic surfactant series was reported by Okahata et al ${ }^{58}$ and Handjani-Vila et $\mathrm{al}^{59}$. They reported formation of vesicular system on hydration of mixture of cholesterol and a single alkyl-chain non ionic surfactant. The resultant vesicles, which have been termed 'niosomes' ,can entrap solutes, are osmotically active, stable ${ }^{60}$ and require non-special conditions such as low temperature or inert atmosphere for production or storage.

*For correspondence Rekha Kumari

Department of Pharmacy,

IEC Group of Institutions, Knowledge Park I, Greater Noida rekha_baghel08@yahoo.co.in, Mob.+919717593957 
Since then a number of non-ionic surfactants have been used to prepare vesicles viz. polyglycerol alkyl ethers $^{59,60,61}$, glycosyl dialkyl ethers ${ }^{62}$, crown ethers ${ }^{63}$, ester linked surfactants ${ }^{64}$, poly-oxyethylene alkyl ether $^{59,65,66}$ and a series of spans and tweens s $^{67,68,69,70}$.

\section{NIOSOMES:}

Niosomes are multilamellar or unilamellar vesicles obtained on hydration of synthetic non-ionic surfactant, with or without incorporation of cholesterol or other lipids $^{2}$. These particles can act as drug reservoir ${ }^{3}$ and have gained wide attention by researchers for their use as drug targeting agents since early 1980s.

The non ionic surfactants for this use are usually single alkyl chain surfactant or sorbitan esters. They are biodegradable, biocompatible and non immunogenic in nature. The size of niosomes is microscopic and lies in nanometric scale.

These vesicles are analogous to the liposomes (phospholipid vesicles). Niosomes represent one of the promising drug delivery systems, with particular interest in delivery applications including nasal, pulmonary, transdermal and ophthalmic delivery. Niosomal vesicles can encapsulate both lipophilic and hydrophilic drugs and protect them against acidic and enzymatic effects in vivo $^{44}$. They behave in vivo like liposomes as they are able to prolong the circulation of encapsulated drug altering its organ distribution and metabolic stability ${ }^{71}$ and release them at a slow rate to sustain the drug effect. Moreover, they can solubilise poorly soluble compounds, providing a tangible strategy to resolve formulation problems of many therapeutic molecules.

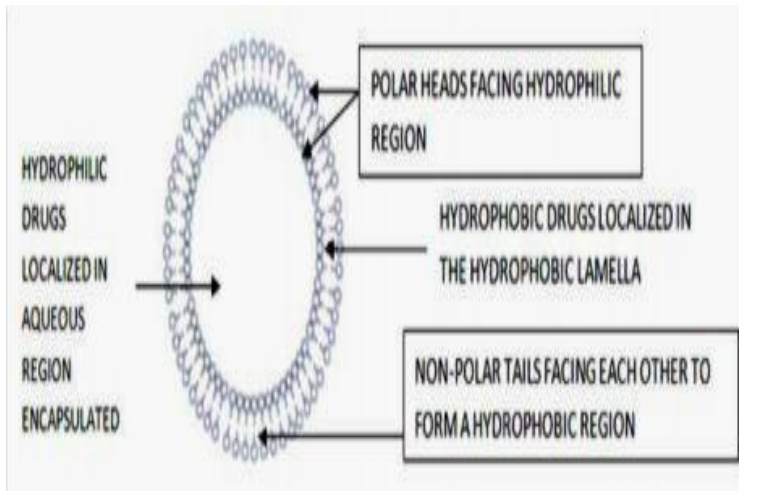

Figure 1: Structure of a Niosome

\section{PREPARATION OF NIOSOMES FROM PRONIOSOMES BY HYDRATION:}

The niosomes can be prepared from the proniosomes (as shown in figure 2) by adding the aqueous phase with the drug to the proniosomes with brief agitation at a temperature greater than the mean transition phase temperature of the surfactant i.e,

$\mathrm{T}>\mathrm{Tm}$

Where,

$\mathrm{T}=$ Temperature

$\mathrm{Tm}=$ Mean phase transition temperature

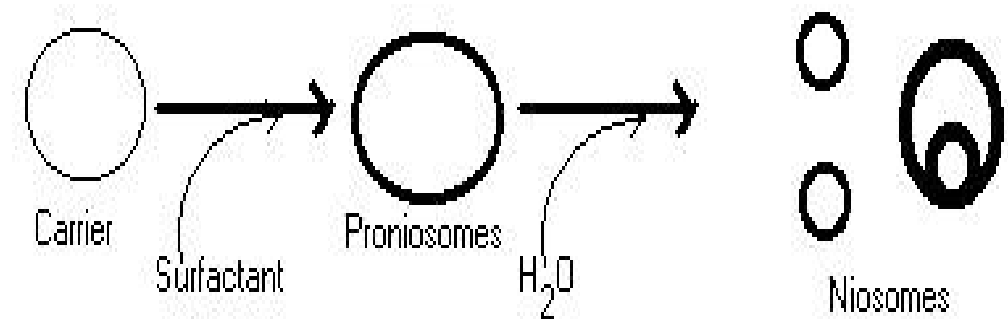

Figure 2: Formation of niosomes from proniosomes

\section{MERITS OF NIOSOMES OVER OTHER VESICLES:}

- They are osmotically stable. Drug molecules with a wide range of solubility can be accommodated in niosomes; they are able to entrap hydrophilic drug by partitioning these molecules into their hydrophobic domain.

- They can reduce drug toxicity because of their nonionic nature.

- Need low cost of production as no special conditions are required for handling and storage of niosomes.

- Non-ionic surfactants are biodegradable, biocompatible and non-immunogenic. Due to the presence of ester bond, phospholipids are easily hydrolyzed ${ }^{51}$.

- They can be tailored according to the desired situation by modifying their structural characteristics (composition, fluidity and size).
- They can enhance performance of drug by improving bioavailability and controlled delivery at a particular site.

- Niosomal dispersion in an aqueous phase can be emulsified in a non-aqueous phase to regulate the delivery rate of drug and administer normal vesicle in external non-ionic phase.

- The vesicle suspension is water-based vehicle. This offers high patient compliance in comparison with oily dosage forms.

- The vesicles may act as a depot, releasing the drug in a controlled manner.

- They improve oral bioavailability of poorly absorbed drugs and enhance skin penetration of drugs.

- They can be made to reach the site of action by oral, parenteral as well as topical routes.

- They improve the therapeutic performance of the drug molecules by delayed clearance from the 
circulation, protecting the drug from biological environment and restricting effects to target cells.

However, they too are associated with some problems. All methods traditionally used for preparation of niosomes are time consuming and many involve specialized equipments. Most of these methods allow only for a predetermined lot size so material is often wasted if smaller quantities are required for particular dose application ${ }^{4}$.

\section{DISADVANTAGES OF NIOSOMES:}

- Physical instability

- Aggregation

- Fusion

- Leaking of entrapped drug

- Hydrolysis of encapsulated drugs which limits the shelf life of the dispersion.

- To overcome these disadvantages, Proniosomes are being taken into consideration.

\section{PRONIOSOMES:}

Proniosomes are dry formulation of water-soluble carrier particles liquid crystalline- compact niosomes hybrid $^{72,39,73}$ that are coated with surfactant and can be measured out as needed and hydrated to form niosomal dispersion immediately before use on brief agitation in hot aqueous media within minutes. The resulting niosomes are very similar to conventional niosomes and more uniform in size ${ }^{5}$

\section{ADVANTAGES OF PRONIOSOMES OVER NIOSOMES: ${ }^{6,7}$}

- They avoid problem of physical stability like aggregation, fusion, leaking.

- Avoid hydration of encapsulated drugs limiting the shelf-life of the dispersion.

- Being a dry product they provide additional convenience of transportation, distribution and storage.

- Furthermore, unacceptable solvents are avoided in proniosomal formulations. These systems are directly formulated into transdermal patches and don't require the dispersion of vesicles into polymeric matrix.

- The storage makes proniosomes a versatile delivery system with potential for use, with a wide range of active compounds.

\section{TYPES OF PRONIOSOMES:}

1. Dry granular proniosomes

2. Liquid crystalline proniosomes

\section{Dry Granular Proniosomes:}

Dry granular proniosomes involves the coating of watersoluble carrier such as sorbitol and maltodextrin with surfactant. The result of coating process is a dry formulation in which each water-soluble particle is covered with thin film of surfactant. It is essential to prepare vesicles at a temperature above the transition temperature of the non-ionic surfactant being used in the formulation. These are further categorized as follows:

\section{(a) Sorbitol based Proniosomes:}

Sorbitol based proniosomes is a dry formulation that involves sorbitol as the carrier, which is further coated with non-ionic surfactant and is used as niosomes within minutes by addition of hot water followed by agitation. These are normally made by spraying surfactant mixture prepared in organic solvent onto the sorbitol powder and then evaporating the solvent. Since the sorbitol carrier is soluble in organic solvent, the process is required to be repeated till the desired surfactant coating has been achieved. The surfactant coating on the carrier is very thin and hydration of this coating allows multilamellar vesicles to form as the carrier dissolves $5,10,11,12$

\section{(b) Maltodextrin based proniosomes:}

A proniosome formulation based on maltodextrin was recently developed that has potential application in deliver of hydrophobic or amphiphilic drugs. The better of these formulations used to hollow particle with exceptionally high surface area. The principal advantage with this formulation was the amount of carrier required to support the surfactant could be easily adjusted and proniosomes with very high mass ratios of surfactant to carrier could be prepared ${ }^{13,14}$.

\section{Liquid Crystalline Proniosomes:}

When the surfactant molecules are kept in contact with water, there are three ways through which lipophilic chains of surfactants can be transformed into a disordered, liquid state called lytorophic liquid crystalline state (neat phase). These three ways are-

- Increasing temperature at kraft point (Tc)

- Addition of solvent, which dissolves lipids

- Using both temperature and solvent.

Neat phase or lamellar phase contains bilayer arranged in sheets over one another within intervening aqueous layer. These types of structures give typical X-ray diffraction and thread like bi-refringent structures under polarized microscope.

\section{FACTORS AFFECTING PHYSICAL NATURE OF PRONIOSOMES:}

There are some factors which can affect significantly the physical nature of proniosomes ${ }^{5}$ such as hydration temperature, choice of surfactant, nature of membrane, nature of drug, etc., (as shown in figure 3 ). 


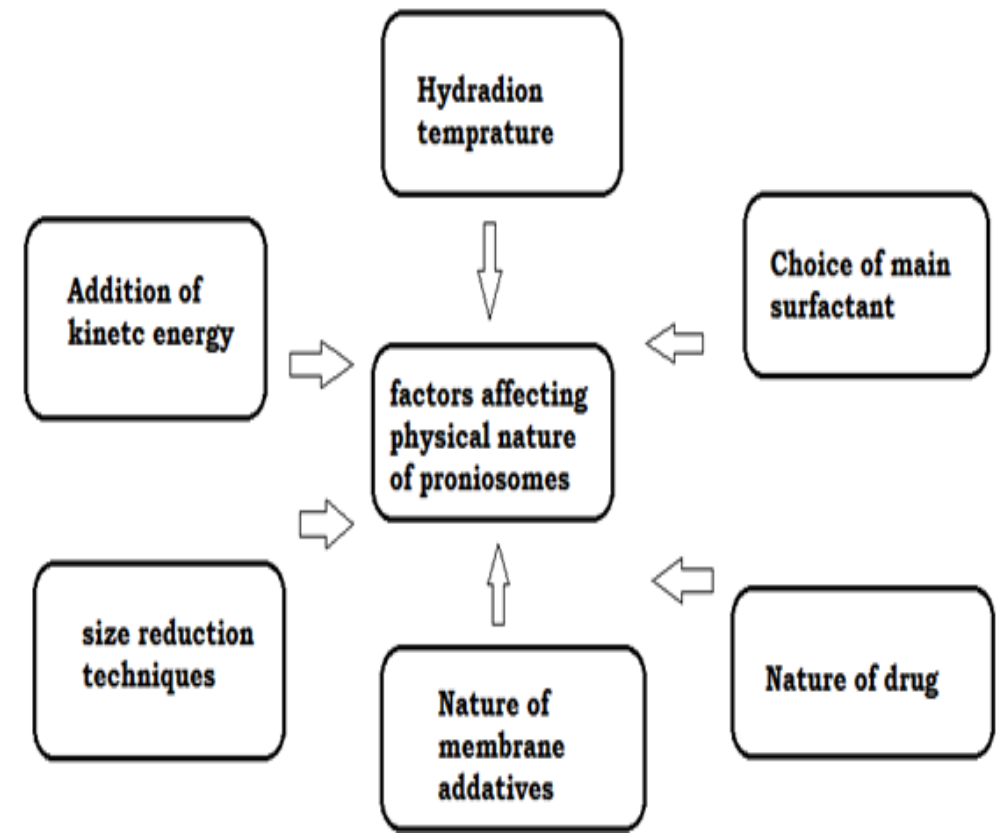

Figure 3: Factors affecting physical nature of proniosomes

\section{PREPARATION OF PRONEOSOMES:}

\section{Materials to be used:}

Different carriers, non-ionic surfactants and membrane stabilizers are used for the proniosome preparation ${ }^{16}$. Commonly used components for proniosomes' formulation are:

Surfactants: Increase drug flux across the $\operatorname{skin}^{56}$, the chemical structure of surfactant influences drug entrapment efficiency. Increments in the alkyl chain length leads to higher entrapment efficiency ${ }^{8}$. It also has been reported that spans having highest phase transition temperature provides highest entrapment for the drug and vice versa. e.g., Tween (20, 40, 60, 80), Span (20, 40, 60).

Selection of surfactant should be done on the basis of HLB value. As Hydrophilic Lipophilic Balance (HLB) is a good indicator of the vesicle forming ability of any surfactant, HLB number in between 4 and 8 has been found to be compatible with vesicle formation. It is also reported that the hydrophilic surfactant owing to high aqueous solubility on hydration do not reach a state of concentrated systems in order to allow free hydrated units to exist aggregates and coalesced to form lamellar structure. The water soluble detergent polysorbate 20 also forms niosomes in the presence of cholesterol. This is despite the fact that the HLB number of this compound is 16.7 Degree of entrapment is affected by the HLB of a surfactant. Transition temperature of surfactants also affects the entrapment of drug in vesicles. Spans with highest phase transition temperature provide the highest entrapment for the drug and vice versa ${ }^{8,9}$.

Span 40 and Span 60 produces vesicles of larger size with higher entrapment of drug. The drug leaching from the vesicles is reduced due to high phase transition temperature and low permeability. High HLB value of Span 40 and 60 results reduction in surface free energy which allows forming vesicles of larger size hence large area exposed to the dissolution medium and skin. No significant difference is observed in the skin permeation profile of formulation containing Span 60 and Span 40 due to their higher phase transition temperature that is responsible for their lower permeability.

The encapsulation efficiency of Tween is relatively low as compared to Span. The drug entrapment efficiency determined by exhaustive dialysis method was lower than that determined by freeze thawing/ centrifugation for both span 40 and span 60 . In freezing, the drug and vesicles are concentrated; particles are closely packed with each other resulting in fusion of niosomal vesicles due to which larger aggregates are formed having high entrapment efficiency ${ }^{74}$. The geometry of vesicle to be formed from surfactants is affected by its structure, which is related to critical packing parameters. On the basis of critical packing parameters of surfactants can predicate geometry of vesicle to be formed.

Critical packing parameters can be defined using following equation, CPP 0.5 micelles form-

$\mathrm{CPP}=\mathrm{V} / \mathrm{lc} \times$ ao

$\mathrm{CPP}=0.5-1$ spherical vesicles form

$\mathrm{CPP}=1$ inverted vesicles form

V - Hydrophobic group volume

lc = the critical hydrophobic group length,

$\mathrm{a} 0=$ the area of hydrophilic head group.

Span 60 is the good surfactant because it has CPP value between 0.5 and 1

\section{Stabilizers:}

Cholesterol -Prevent leakage of drug formulation.

Lecithin -Penetration enhancer e.g., Soya and Egg lecithin $^{57}$

Lecithin: Phosphotidylcholine is the major component of lecithin. The name basically depends upon their source of origin such as soya lecithin from soya beans and egg lecithin from egg yolk. Phosphotidylcholine has 
low solubility in water ${ }^{16}$. Incorporation of lecithin in proniosomes may act as permeation enhancer, prevents the leakage of drug and enhanced the percent drug entrapment due to high phase transition temperature. However, the incorporation of lecithin into formulation requires special treatment during preparation and storage, which makes the product less stable and highly expensive. So, it may be suggested to prepare proniosomes devoid of lecithin component ${ }^{74}$. The vesicles composed of soya lecithin are of larger size then vesicle composed of egg lecithin due to difference in the intrinsic components. On the basis of penetration capability the soya lecithin is considered as a good candidate as it contains unsaturated fatty acids, oleic and linoleic acid while egg lecithin contains fatty acids ${ }^{17}$.

Cholesterol: Cholesterol is an essential component of vesicles. Incorporation of cholesterol influence vesicles stability and permeability ${ }^{18}$. Concentration of cholesterol plays an important role in entrapment of drug in vesicles. The incorporation of cholesterol delay drug release in vitro $^{75}$. The entrapment efficiency and permeation increases with increasing cholesterol content and by the usage of span 60 which has higher transition temperature ${ }^{19}$. On further increase in cholesterol beyond certain concentration level starts disrupting the regular bi-layered structure leading to loss of drug entrapment and permeation ${ }^{20}$. Above the phase transition temperature cholesterol makes the membrane more ordered and abolish the gel to liquid phase transition of noisomal system, thus preventing drug leakage from proniosomes $^{8,76}$. Solvent selection of solvent is another important aspect as it has great effect on vesicle size and drug permeation rate $^{21}$. Vesicles formed from different alcohols are of different sizes and they follow the order: ethanol > propanol > butanol > isopropanol. Higher size of vesicles in case of ethanol is due to its greater solubility in water and smallest size of isopropanolol, may be due to branched chain present in $i^{22}$. Ethanol may cause the reduction of lipid polar head interactions within the membrane, thereby increased the skin permeation $^{23,24}$.

Aqueous phase: Enhances drug entrapment efficiency of vesicles e.g., Hot water, Buffer, Glycerol.

Phosphate buffer $7.4,0.1 \%$ glycerol and hot water are mainly used aqueous phase for proniosomes. $\mathrm{pH}$ of the hydrating medium also play important role in entrapment efficiency. The aqueous medium might influence the tactness of proniosomes, thus affecting their entrapment efficiency $^{25,26}$.

Sugar: Provides flexibility in surfactant and other component ratio alters the drug distribution e.g., Maltodextrin, Sorbitol Carrier which is selected for proniosomes' preparation should have characteristics like free flow ability, non-toxicity, poor solubility in the loaded mixture solution and good water solubility for ease of hydration.

Maltodextrin: is a polysaccharide. It has minimal solubility in organic solvent. Thus it is possible to coat maltodextrin particles by simply adding surfactant in organic solvent. The use of maltodextrin as carrier in Proniosomes preparation permitted flexibility in the ratio of surfactant and other components which can be incorporated. Coating sorbitol results in solid cake like mass.

Solvent: Enhance skin permeation e.g., Ethanol, Methanol, Propanolol, Isopranolol.

\section{METHODS OF PREPARING PRONIOSOMES:}

\section{Slurry method:}

Proniosomes can be prepared from a stock solution of surfactants and cholesterol in suitable solvent. The required volume of surfactant and cholesterol stock solution per gram of carrier and drug should be dissolved in the solvent in round bottom flask containing the carrier (maltodextrin or lecithin). Additional chloroform can be added to form the slurry in case of lower surfactant loading. The flask has to be attached to a rotary flash evaporator to evaporate solvent at 50-60 rpm at a temperature of $45 \pm 20 \mathrm{C}$ and a reduced pressure of $600 \mathrm{~mm}$ of $\mathrm{Hg}$ until the mass in the flask had become a dry, free flowing product. Finally, the formulation should be stored in tightly closed container under refrigeration in light ${ }^{7,14}$.

\section{Spray coated method:}

A $100 \mathrm{ml}$ round bottom flask containing desired amount of carrier can be attached to rotary flash evaporator. A mixture of surfactant and cholesterol should be prepared and introduced into round bottom flask on rotary evaporator by sequential spraying of aliquots onto carrier's surface. The evaporator has to be evacuated and rotating flask can be rotated in water bath under vacuum at $65-70{ }^{0} \mathrm{C}$ for $15-20 \mathrm{~min}$. This process has to be prepared until all of the surfactant solution had been applied. The evaporation should be continued until the powder becomes completely dry ${ }^{5,28,29}$.

\section{Coacervation phase separation method:}

Accurately weighed or required amount of surfactant, carrier (lecithin), cholesterol and drug can be taken in a clean and dry wide mouthed glass vial $(5 \mathrm{ml})$ and solvent should be added to it. All these ingredients have to be heated and after heating all the ingredients should be mixed with glass rod. To prevent the loss of solvent, the open end of the glass vial can be covered with a lid. It has to be warmed over water bath at $60-70{ }^{0} \mathrm{C}$ for 5 minutes until the surfactant dissolved completely. The mixture should be allowed to cool down at room temperature till the dispersion gets converted to a Pronisomal gel ${ }^{30}$

\section{METHODS FOR CHARACTERIZATION OF PRONIOSOMES:}

\section{Vesicle morphology:}

Vesicle morphology involves the measurement of size and shape of proniosomal vesicles. Size of proniosomal vesicles can be measured by dynamic light scattering method in two conditions: without agitation and with agitation. Hydration without agitation results in largest vesicle size.

\section{Shape and surface morphology:}


Surface morphology means roundness, smoothness and formation of aggregation. It is studied by scanning electron microscopy, optical microscopy, transmission electron microscopy ${ }^{31}$.

\section{Scanning electron microscopy:}

The proniosomes are sprinkled onto the double-sided tape that is to be affixed on aluminum stubs. The aluminum stub is placed in the vacuum chamber of a scanning electron microscope. The samples are observed for morphological characterization using a gaseous secondary electron detector (working pressure: 0.8 tor, acceleration voltage: 30.00 KV) XL 30, (Philips, Netherlands) $)^{7,14}$.

\section{Optical microscopy:}

The niosomes are mounted on glass slides and viewed under a microscope with magnification of $1200 \mathrm{X}$ for morphological observation after suitable dilution. The photomicrograph of the preparation also obtained from the microscope by using a digital SLR camera ${ }^{32}$.

\section{Transmission electron microscopy:}

The morphology of hydrated niosome dispersion is determined using transmission electron microscopy. A drop of niosome dispersion is diluted 10-fold using deionized water. A drop of diluted niosome dispersion is applied to a carbon coated 300 mesh copper grid and is left for $1 \mathrm{~min}$ to allow some of the niosomes to adhere to the carbon substrate. The remaining dispersion is removed by adsorbing the drop with the corner of a piece of filter paper. After twice rinsing the grid (deionized water for 3-5 s) a drop of $2 \%$ aqueous solution of uranyl acetate is applied for $1 \mathrm{~s}$. The remaining solution is removed by absorbing the liquid with the tip of a piece of filter paper and the sample is air dried. The sample is observed at $80 \mathrm{kv}$.

\section{Angle of repose:}

The angle of repose of dry proniosomes powder is measured by a funnel method. The proniosomes powder is poured into a funnel which is fixed at a position so that the $13 \mathrm{~mm}$ outlet orifice of the funnel is $5 \mathrm{~cm}$ above a level black surface. The powder flows down from the funnel to form a cone on the surface and the angle of repose was then calculated by measuring the height of the cone and the diameter of its base $\mathrm{s}^{5,12,14,27,33}$.

7. Rate of hydration: Neubaur's chamber.

8. Drug content:

Drug can be quantified by a modified HPLC method.

\section{Penetration and permeation studies:}

Depth of penetration in proniosomes can be visualized by confocal laser scanning microscopy (CLSM).

\section{Encapsulation efficiency:}

The encapsulation efficiency of proniosomes is determined after separation of the unentrapped drug.

A. Separation of unentrapped drug is done by the following techniques:

(a) Dialysis:
The aqueous niosomal dispersion is dialyzed tubing against suitable dissolution medium at room temperature then samples are withdrawn from the medium at suitable time interval centrifuged and analyzed for drug content using UV spectroscopy ${ }^{32}$.

(b) Gel filtration:

The free drug is removed by gel filtration of niosomal dispersion through a sephadex G50 column and separated with suitable mobile phase and analyzed with analytical techniques ${ }^{34}$.

(c) Centrifugation:

The niosomal suspension is centrifuged and the surfactant is separated. The pellet is washed and then resuspended to obtain a niosomal suspension free from unentrapped drug ${ }^{15}$.

\section{B. Determination of entrapment efficiency of proniosomes:}

The vesicles obtained after removal of unentraped drug by dialysis is then resuspended in 30\% v/v of PEG 200 and $1 \mathrm{ml}$ of $0.1 \% \mathrm{v} / \mathrm{v}$ triton $\mathrm{x}-100$ solution was added to solubilize vesicles the resulted clear solution is then filtered and analyzed for drug content. The percentage of drug entrapped is calculated by using the following formula ${ }^{35}$ :

Percent Entrapment $=$ Amount of drug entrapped/total $\times$ 100

\section{Drug Release Kinetics and Data Analysis:}

In order to understand the kinetics and mechanism of drug release, the result of in-vitro drug release study of noisome are fitted with various kinetic equations like,

(a) Zero order, as cumulative $\%$ release vs. time,

$$
\mathrm{C}=\mathrm{KOt}
$$

Where,

$\mathrm{k} 0=$ zero order constant expressed in units of concentration/time

$\mathrm{t}=$ time in hours

(b) Higuchi's model, as cumulative \% drug release vs. square root of time.

$$
\mathrm{Q}=\mathrm{KHt}_{1 / 2}
$$

Where,

$\mathrm{KH}=$ higuchi's square root of time kinetic drug release constant.

(c) Peppa's model, as log cumulative \% drug release vs. $\log$ time and the exponent ' $\mathrm{n}$ ' was calculated through the slope of the straight line.

$$
\mathrm{M}_{\mathrm{t}} / \mathrm{M}_{0}=\mathrm{btn}
$$

Where,

$\mathrm{M}_{\mathrm{t}}=$ amount of drug release at time $\mathrm{t}$

$\mathrm{M}_{0}=$ overall amount of the drug

$\mathrm{b}=\mathrm{constant}$ 
$\mathrm{n}=$ release exponent indicative of the drug release mechanism

If the exponent $n=0.5$ or near, then the drug release mechanism is Fickian diffusion, and if $\mathrm{n}$ have near 1.0 then it is Non-Fickian diffusion ${ }^{34}$.

\section{In-Vitro Methods for Assessment of Drug Release from Proniosomes \\ (a) Dialysis tubing:}

This apparatus has prewashed dialysis tubing, which can be hermetically sealed. The dialysis sac is then dialyzed against a suitable dissolution medium at room temperature; the samples are withdrawn from the medium at suitable intervals, centrifuged and analyzed for drug content using suitable method (UV spectroscopy, HPLC etc.). The maintenance of sink condition is essential ${ }^{36}$.

\section{(b) Reverse dialysis:}

In this technique a number of small dialysis tubes containing $1 \mathrm{ml}$ of dissolution medium are placed. The proniosomes are then displaced into the dissolution medium. The direct dilution of the proniosomes is possible with this method; however the rapid release cannot be quantified using this method ${ }^{36}$.

\section{(c) Franz diffusion cell:}

The in-vitro studies can be performed by using Franz diffusion cell. Proniosomes are placed in the donor chamber of a Franz diffusion cell fitted with a cellophane membrane. The proniosomes is then dialyzed against suitable dissolution medium at room temperature; the samples are withdrawn from the medium at suitable intervals, and analyzed for drug content using suitable method (UV spectroscopy, HPLC etc.). The maintenance of sink condition is essential ${ }^{37}$.

\section{(d) Zeta potential analysis:}

Zeta potential analysis is done for determining the colloidal properties of the prepared formulations. The suitably diluted proniosomes derived niosome dispersion is determined using zeta potential analyzer based on Electrophorectic light scattering and laser Doppler Velocimetery method. The temperature is set at $25^{\circ} \mathrm{C}$. Charge on vesicles and their mean zeta potential values with standard deviation of 5 measurements are obtained directly from the measurement ${ }^{38}$.

\section{Stability Studies:}

Stability studies are carried out by storing the prepared proniosomes at various temperature conditions like refrigeration $\left(2^{\circ}-8^{\circ} \mathrm{C}\right)$, room temperature $\left(25^{\circ} \pm 0.5^{\circ} \mathrm{C}\right)$ and elevated temperature $\left(45^{\circ} \mathrm{C} \pm 0.5^{\circ} \mathrm{C}\right)$ from a period of one month to three months. Drug content and variation in the average vesicle diameter are periodically monitored. ICH guidelines suggests stability studies for dry proniosomes powder meant for reconstitution should be studied for accelerated stability at $75 \%$ relative humidity as per international climatic zones and climatic conditions $27,39,40$

\section{APPLICATIONS OF PRONEOSOMES:}

\section{Drug targeting: $:^{53}$}

One of the most useful aspects of proniosomes is their ability to target drugs. Proniosomes can be used to target drugs to the reticulo-endothelial system. The reticuloendothelium system ${ }^{52}$ (RES) preferentially takes up proniosomes vesicles. The uptake of proniosomes is controlled by circulating serum factors called opsonins. These opsonins mark the niosomes for clearance. Such localization of drugs is utilized to treat tumors in animals known to metastasize the liver and spleen $^{51}$. This localization of the drugs can also be used for treating parasitic infections of the liver. Proniosomes can also be utilized for targeting drugs to organs other than the RES. A carrier system (such as antibodies) can be attached to proniosomes (as immunoglobin bind readily to the lipid surface of the noisome) to target them to specific organs ${ }^{53}$. Many cells also possess carbohydrates determinates, and this can be exploited by niosomes to direct carrier system to particular cells.

\section{Anti-neoplatic treatment: ${ }^{41,42}$}

Most antineoplastic drugs cause severe side effects. Proniosomes can alter the metabolism; prolong circulation and half life of the drug, thus decreasing the side effects of the drugs.

\section{Treatment of leishmaniasis: ${ }^{43}$}

Leishmanasis is a disease in which a parasite of the genus Leishmania invades the cells of the liver and spleen. Commonly prescribed drugs for the treatment are derivatives of antimony (antimonials), which in higher concentrations can cause cardiac, liver and kidney damage.

\section{Delivery of peptide drugs: $:^{44}$}

Oral peptide drug delivery has long been faced with a challenge of bypassing the enzymes which would breakdown the peptide. Use of proniosomes to successfully protect the peptides from gastrointestinal peptide breakdown is being investigated. In an in-vitro study, oral delivery of a Vasopressin derivative entrapped in proniosomes showed that entrapment of the drug significantly increased the stability of the peptide.

\section{Uses in studying immune response: ${ }^{45}$}

Proniosomes are used in studying immune response due to their immunological selectivity, low toxicity and greater stability. Proniosomes are being used to study the nature of the immune response provoked by antigens.

\section{Niosomes as carriers for haemoglobin: ${ }^{46}$}

Proniosomes can be used as carriers for haemoglobin within the blood. The proniosomal vesicle is permeable to oxygen and hence can act as a carrier for haemoglobin in anaemic patients.

\section{Transdermal drug delivery systems: ${ }^{47}$}

One of the most useful aspects of proniosomes is that they greatly enhance the uptake of drugs through the skin. Transdermal drug delivery utilizing proniosomal technology is widely used in cosmetics; In fact, it was one of the first uses of the niosomes ${ }^{54}$. Topical use of proniosome entrapped antibiotics to treat acne is done. The penetration of the drugs through the skin is greatly increased as compared to un-entrapped drug ${ }^{55}$. Recently, 
transdermal vaccines utilizing proniosomal technology is also being researched. The proniosome (along with liposomes and transferomes) can be utilized for topical immunization using tetanus toxoid. However, the current technology in proniosomes allows only a weak immune response, and thus more research to be done in this field.

\section{Sustained release: ${ }^{48}$}

Sustained release action of proniosomes can be applied to drugs with low therapeutic index and low water solubility since those could be maintained in the circulation via proniosomal encapsulation.

\section{Localized drug action: ${ }^{27,49}$}

Drug delivery through proniosomes is one of the approaches to achieve localized drug action, since their size and low penetrability through epithelium and connective tissue keeps the drug localized at the site of administration. Localized drug action results in enhancement of efficacy of potency of the drug and at the same time reduces its systemic toxic effects e.g. Antimonials encapsulated within proniosomes are taken up by mononuclear cells resulting in localization of drug, increase in potency and hence decrease both in dose and toxicity. The evolution of proniosomal drug delivery technology is still at an infancy stage, but this type of drug delivery system has promise in cancer chemotherapy and anti-leishmanial therapy.

\section{Cosmetics or Cosmeceuticals: ${ }^{15}$}

Proniosome gel can be used as-an effective delivery systems for cosmetics and Cosmeceuticals due to their unique properties ${ }^{50}$. For applying therapeutic and cosmetic agents onto or through skin requires a non toxic, dermatologically acceptable carrier, which not only control the release of the agent for prolong action but also enhances the penetration to the skin layer. Proniosomes gel formulation shows advantages in controlled drug delivery improved bioavailability, reduced side effects and entrapment of both hydrophilic and hydrophobic drugs ${ }^{15}$.

\section{CONCLUSION:}

Proniosomes are promising drug carriers for the future with greater physical and chemical stability and potentially scalable for commercial viability. The delivery system holds promise for the effective drug delivery for amphiphilic drugs. Various types of drug deliveries can be possible using proniosomes based niosomes like targeting, ophthalmic, topical, parenteral, oral vaccine etc. More researches are carried out in this field to know the exact potential in this novel drug delivery system. Proniosomes has attracted a great deal of attention for the delivery of drugs through transdermal route because of the advantages like non-toxicity and penetration enhancing effect of surfactants and effective modification of drug release properties. Proniosomes in dry powder form makes the possibility of convenient unit dosing as the proniosome powder can further be processed to make beads, tablets or capsules. The findings of the studies on proniosomes till date, opens the door for the future use of different carrier materials with biocompatibility and suitability for the preparation of proniosomes. However, future experiments should explore the suitability of proniosomes with more drugs having defined drawbacks for improved and effective intended therapy. Studies should be explored to assess the ability of different carrier materials to formulate proniosomes and the ability of proniosomes to deliver the drugs meant for administration through various routes.

\section{REFERENCES}

1. Thejaswi C, Rao M, Gobinath M, Radharani J, Hemafaith V, Venugopalaiah P, A review on design and characterization of proniosomes as a drug carrier, IJAPN, 1, 2011, 16

2. Handjani V, Dispersions of lamellar phases of non-ionic lipids in cosmetics products, Int. J. Cos. Sci., 1, 1979, 303-314. 3.

3. Fahima H, Mohamed EIR, Mohamed N, Yasmin A. Preparation and characterization of niosomes containing ribavirin for liver targeting. Drug Deliv 2010; 17(5): 282-287.

4. Malhotra M. and Jain NK: Niosomes as Drug Carriers. Indian Drugs. 1994; 31 (3): 81-86.

5. Hu C, and Rhodes DG, Proniosomes: A novel drug carrier preparation, Int. J. Pharm., 185, 1999, 23-25.

6. Pandey N, Proniosomes and ethosomes: New prospect in transdermal and dermal drug delivery system, IJPSR, 2(8), 2011, 1988-1996.

7. Mahdi, Jufri, Effionora, Anwar, Joshita, Djajadisastra, Preparation of Maltodextrin DE 5-10 based Ibuprofen Proniosomes, Majalah Ilmu kefarmasian, 1, 2004, 10-20.

8. Hao Y, Zhao F, Li N, Yang Y, Li k, Studies on a high Encapsulation of colchine by a niosome system, Int. Pharm., 244, 2002, 73-80.

9. Yoshioka T, Sternberg B, Florence AT, Preparation and properties of vesicles (niosomes) of sorbitan monoesters (span 20, 40,60 and 80) and a sorbitan lriester (span 85), Int. J. Pharm., 105, 1994, 1-6.

10. Arunotharyanun P, Bernard MS, Craig DQH, Uchegbu TF, Florenace AT, The effect of processing variables on the physical characteristics of non-ionic surfactant vesicles

(niosomes) formed from a hexadecyl diglycerol ether, Int. J. Pharm., 201, 2000, 7.

11. Welesh AB, Rhodes DG, Maltodextrin based proniosomes, Pharm. Sci., 3, (2001a), 1

12. Welesh AB, Rhodes DG, SEM imaging predicts quality of niosomes from maltodextrin based proniosomes, Pharm. Res., 18, (2001b), 656.

13. Mahdi, Jufri, Effionora, Anwar, Joshita, Djajadisastra, Preparation of Maltodextrin DE 5-10 based Ibuprofen Proniosomes, Majalah Ilmu kefarmasian, 1, 2004, 10-20.

14. Almira I, welesh AB, Rhodes DG, Maltodextrin based proniosomes, AAPS Pharm. Sci. tech., 3(1), 2001, article 1.

15. Souto EB, Muller RH. Cosmetic features and application of lipid nanoparticles (SLN, NLC). Int J Cosmetic Science 2008; 30: $157-165$

16. Reddy DN, Udupa N. Formulation and evaluation of oral and transdermal preparations of flurbiprofen and piroxicam incorporated with different carriers. Drug Dev Ind Pharm 1993; 19: 843-852.

17. Valenta C, Wanka M, Heidlas J. Evaluation of novel soyalecithin formulations for dermal use containing ketoprofen as a model drug. J Control. Rel 2000; 63: 165-173.

18. Nasseri B. Effect of cholesterol and temperature on the elastic properties of niosomal membranes. Int J Pharm 2005; 300: 95 101.

19. Fang JY, Hong CT, Chiu WT, Wang YY. Effect of liposomes and niosomes on skin permeation of Enoxacin. Int $\mathrm{J}$ Pharm 2001; $21: 61-72$. 
20. Finean JB. Interaction between cholesterol and phospholipid in hydrated bilayers. Chem Phy Lipids 1990; 54: 147-156.

21. Lopez JM, Gonzalez ML, Rabasco AM. Effect of cholesterol and ethanol on dermal delivery from DPPC liposomes. Int $\mathbf{J}$ Pharm 2005; 298: 1-12.

22. Ishii F, Takemura A, Ishigami Y. Procedure for preparation of lipid vesicles (Liposomes) using coacervation (phase separation) technique. Langmuir 1995; 11: 483-486.

23. Parikh DK, Ghosh TK. Feasibility of transdermal delivery of fluoxetine. AAPS PharmSciTec 2005; 6(2): 144-149.

24. Annakula D, Errabelli MR, Jukanti R, Bandari S, Veerareddy PR. Provesicular drug delivery systems: An overview and appraisal. Arch Appl Sci Res 2010; 2(4): 135-146.

25. Megrab NA, Williams AC, Barry BW. Oestradiol permeation across human skin, silastic and snake skin membranes: The effects of ethanol/water cosolvent systems. Int J Pharm 1995; 116: 101-112

26. Sudaxshiina M, Benedicte VD, Gregory G, Alexander TF. Water in sorbitan monostearate organogels (water in oil gels). J Pharm Sci 1999; 88(6): 615-619.

27. Solanki AB Parikh RH, Formulation and optimization of proxicam proniosomes, AAPS Pharma. Sci. Tech., 8(4), 2007, 86.

28. Jain NK, Controlled and novel drug delivery system, $1^{\text {st }}$ Edition, 302, CBS publishers and distributors, New Delhi, 2003, 270

29. Khandare JN, Madhavi G, Tamhankar BM, Niosomal novel drug delivery system, The eastern Pharmacist, 37, 1994, 61-64

30. Ijeoma F, Uchegbu, Suresh P. Vyas, Non-ionic surfactant based vesicles (niosomes) in drug delivery, Int. J. Pharm., 172, 1998, 33-70.

31. Yoshioka T, Sternberg B, Florence AT, Preparation and properties of vesicles (niosomes) of sorbitan monoesters (span 20, 40, 60 and 80) and a sorbitan lriester (span 85), Int. J. Pharm., 105, 1994, 1-6.

32. Solanki A, Parkihk $\mathrm{J}$ and Parikh R, Preparation, characterization, optimization and stability studies of Aceclofenac proniosomes, Iranian. J. Pharm Research, 7(4), 2008, 237-246

33. Chauhan S, Luorence MJ, The preparation of polyxyethylene containing non-ionic surfactant vesicles, J. Pharm. Pharmacol., 41, 1989, 6 .

34. Gibaldi $M$ and Perrier D, Pharmacokinetics, 2nd Edition, Marcel Decker, New York, 1982.

35. Vora B, Khopade AJ, Jain NK, Proniosome based transdermal delivery of levonogesterol for effective contraception, J. Control. Rel. 54, 1998,149.

36. Muller RH, Radtke M, Wissing SA, Solid lipid nanoparticles lipid carriers (NLC) in cosmetic and dermatological preparations, Adv. Drug delivery Rev., 54, 2002, 131-155.

37. Pugalia C, Trombetta D, Venuti V, Saija A, Bonina, Evaluation of in-vitro topical anti-inflammatory activity of Indomethacin from liposomal vesicles, J. Pharm. Pharmacol., 56, 2004, 1225 1232.

38. Junyaprasert VB, Teeranachaideekul V, Supaperm T, Effects of charged and non-ionic membrane additives on physicochemical properties and stability of niosomes, AAPS Pharm. Sci. Tech., 9(3), 2008, 851-859.

39. Gupta A, Prajapati S.K, Balamurugan M, 2007. Design and development of a proniosomal drug delivery system for captropril. Trop. J. Pharm. Res.6, 687-693

40. Raymond CR, Paul JS, Sian CO, Handbook of pharmaceutical excipients, 5th Edition, Pharmaceutical Press, Great Britain, 2006, 580-584.

41. Azmin MN, Florence AT, Handjani-Vila RM, Stuart JFB, Vanlerberghe $\mathrm{G}$ and Whittaker JS, The effects of non-ionic surfactant vesicle (niosome) entrapment on the absorption and distribution of methotrexate in mice, J. Pharm. Pharmacol., 37, 1985, 237-242.

42. Ruckmani K, Jayakar B, Ghosai SK, Non-ionic surfactan vesicles (niosomes) of cytarabine hydrochloride for effective treatment of leukemias: Encapsulation, storage and in vitro release, Drug Dev. Ind. Pharm., 26, 2002, 217-222.

43. Hunter CA, Dolan TF, Coombs GH and Baillie AJ, Vesicular systems (niosomes and liposomes) for delivery of sodium stibogluconate in experimental murine visceral leishmaniasis, J. Pharm. Pharmacol., 40(3), 1988, 161-165.

44. Yoshida H, Lehr CM, Kok W, Junginger HE, Verhoef JC and Bouwistra JA, Niosomes for oral delivery of pepetide drugs, J. Control Rel., 21, 1992, 145-153.

45. Brewer JM and Alexander JA, The adjuvant activity of nonionic surfactant vesicles (niosomes) on BALB/C humoral response to bovine serum albumin, Immunology, 75(4), 1992, 570-575

46. Moser P, Marchand-Arvier M, Labrude P, Handjani Vila RM and Vigerson C, Niosomes d' hemoglobine, IPreparation, properietes physicochimiques et oxyphoriques, stabilite. Pharma., Acta.Helv., 64(7), 1989, 1992-202

47. Satturwar PM, Fulzele SV, Nande VS, Khandare JN, Formulation and evaluation of ketoconazole niosomes, Indian J. Pharm., 64(2), 2002, 155-158.

48. Jain NK, Ramteke S, Maheshwari U, Clarithromycin based oral sustained release nanoparticle drug delivery system, Indian J. Pharm. Sci., 68(4), 2006, 479.

49. Uchegbu IF, Double JA, Turton JA, Florence At, Niosome encapsulation of a doxorubicin polymer conjugates, Pharmaceutical Research, 12, 1995, 1019-24.

50. Shamsheer Ahmad S, Sabareesh M, Patan Rafi Khan, Sai krishna P, Sudheer B. Formulation and Evaluation of Lisinopril Dihydrate Transdermal Proniosomal Gels. Journal of Applied Pharmaceutical Science 2011; 01(08): 181-185

51. Kemps J, Crommelin DA, Hydrolyse van fosfolipiden in watering milieu, Pharm. Weekbl., 123, 1988, 355-363.

52. Devaraj GN, Prakash SR, Devaraj R, Apte SS, Rao BR, Rambhav D, Release studies on niosomes containing fatty alcohols as bilayer stabilizers instead of cholesterol, Journal of colloidal and interface science, 251, 2002, 360-365

53. Gregoriadis $\mathrm{G}$, Targeting of drugs: Implications in medicines. Lancet, 2(8240), 1981, 241-246.

54. Shahiwala A, Misra A, Studies in topical application of niosomically entrapped nimesulide, J. Pharm. Sci. 5(3), 2002, 220-225.

55. Faiyaz S, Baboota S, Ahuja A, Ali J, Aquil M, Shafiq S, Nanoemulsions as vehicles for Transdermal delivery of Aceclofenac, AAPS Pharm. SCi. Tech., 8(4), 2007, Article 104.

56. Hofland H, Geest RV, Bodde H, Junginger H, Boustra J. Estradiol permeation from non ionic surfactant vesicles through human stratum corneum in vitro. Pharmaceut Res 1994; 11: 659- 664

57. Runothayanun P, Sooksawate T, Florence AT. Extrusion of niosomes from capillaries: approaches to pulsed delivery device. J Control Release 1999; 60(2): 391-397.

58. Y. Okahata, M. Nagai, and T. Kunitake., J. Colloid Interface Sci., 1981, 82, 401 .

59. M. Handjani-vila , A. Ribier , B. Rondot and G. Vanlerberghe., Int. J. Cosmet. Sci., 1979,1,303.

60. AJ. Baillie, AT. Florence, LR. Hume, GT. Muirhead and A. Rogerson., J. Pharm. Pharmacol, 1985, 37, 863.

61. AJ.Baillie, GH.Coombs, TF. Dolan and J.Laurie., J. Pharm. Pharmacol., 1986, 38,502.

62. H. Kiwada, H. Nimura and Y. Kato., Chem. pharm. Bull., 1985, 33, 2475.

63. L.E. Echegoyen, J.C. Hernandez, AE. Kaifer, GW. Gokel and L.Echegoyen., J. Chem. Soc. Chem.Comm., 1988, 12, 836.

64. CA. Hunter, TF. Dolan, LH.Coombs and AJ Baillie., J. Pharm. Pharmacol., 1988, 40,161.

65. HEG. Hofland, JA. Bouwstra , M. Ponec, HE. Bodde , F. Spies , H. Verhoef and HEG. Junginger. J. Control Rel. 1991, 16,155 .

66. HEG. Hofland, JA. Bouwstra, JC. Verhoef, G. Buckton, BZ. Chowdry, M. Ponec and HEG.

67. Junginger. Pharm. Pharmacol., 1992, 44, 287.

68. RA. Raja Naresh, UV. Singh, N. Udupa and GK. Pillai., Indian Drugs. , 993, 30, 278.

69. G. ParthaChandra Prakash, N. Udupa, P. Umadevi and GK .Pillai., Int. J. Pharm., 1990, 61

70. KS. Chandra Prakash, N. Udupa, P. Umadevi and GK .Pillai., Int. J. Pharm., 1990, 61, R1. 
71. KS. Chandra Prakash , N. Udupa, P. Umadevi and GK.Pillai., Ind. J. Pharm. ,1992, 54, 197.

72. Rogerson A, Cummings J, Willmott N, 1988. The distribution of doxorubicin in mice following administration in niosomes. $\mathrm{J}$. Pharm. Pharmacol. 40, 337-342.

73. Fang J.Y, Yu S.Y, Wu P.C, 2001. In vitro permeation of estradiol from various proniosome formulations. Int. J. Pharm. 215, 91-99.

74. Varshosaz J, Pardakhty A, Seied M.H.B, 2005. Sorbitan monopalmitate based proniosomes for transdermal delivery of cholpheniramine maleate. Drug Deliv. 12, 75-82.
75. Mokhtar M, Sammour O.A, Hammad M.A, 2008. Effects of some formulation parameters on florbiprofen encapsulation and release rates of niosomes prepared from proniosomes. Int. J. Pharm. 361, 104-111.

76. Namdeo A, jain n.k, 1999. Niosomal delivery of 5-fluorouracil. J. microencapsul. 16, 731-740.

77. Cable C, 1989. An examination of the effects of surface modifications on the physicochemical and biological properties of non-ionic surfactant vesicles. Ph.D. Thesis. University of strathclyde, Glasgow, UK. 